\title{
Impact Thickness on Structural and Electrical Characterization of Nickel Phthalocyanine Thin Films
}

\author{
Eman M. Nasir'1, Mohammed T. Hussein'1, Addnan H. Al-Aarajiy ${ }^{2}$ \\ ${ }^{1}$ Department of Physics, College of Science, University of Baghdad, Baghdad, Iraq \\ ${ }^{2}$ Department of Physics, College of Science, University of Babylon, Babylon, Iraq \\ Email: eman.itabi@gmail.com
}

How to cite this paper: Nasir, E.M., Hussein, M.T. and Al-Aarajiy, A.H. (2019) Impact Thickness on Structural and Electrical Characterization of Nickel Phthalocyanine Thin Films. Advances in Materials Physics and Chemistry, 9, 123-132.

https://doi.org/10.4236/ampc.2019.97010

Received: March 31, 2019

Accepted: July 28, 2019

Published: July 31, 2019

Copyright $\odot 2019$ by author(s) and Scientific Research Publishing Inc. This work is licensed under the Creative Commons Attribution International License (CC BY 4.0).

http://creativecommons.org/licenses/by/4.0/

\section{Open Access}

\begin{abstract}
Thin films of Nickel Phthalocyanine have been prepared by evaporation technique for $(50-350 \mathrm{~nm})$ of thickness. XRD studies show that the thin films have single crystalline structure for low thicknesses with (100) orientation and the crystallite size increased with increased thickness. Also from the AFM technique for NiPc films, the roughness was determined and the grain size increases with increasing of thickness from except at thickness $350 \mathrm{~nm}$. The studies of electrical properties, morphology and orientations of the crystallites are important to understand and predict the nature of the films and essential for their successful applications in solar cell and sensors. The electrical properties of these films were studied with different thickness, NiPc has three activation energy. Carrier's concentration and mobility was calculated. Hall measurements showed that all the films are p-type.
\end{abstract}

\section{Keywords}

Nickel Phthalocyanine, Vacuum Evaporation, XRD, AFM, Morphology, Thin Film, Electrical Properties

\section{Introduction}

Nowadays, semiconducting organic materials are very important since they have successful application in optical and electronic devices. One of these materials is Phthalocyanines (Pcs); it has significant properties which made it a good alternative for development electronic devices. These materials have been used in the gas sensor and in electronic devices because it possesses many advantageous properties such as thermal, chemical and photochemical stability, excellent film 
growth and good optical and electronic properties [1]. Their thermally stable nature makes them suitable for thin film deposition by thermal sublimation. These materials have also shown promise for photoconductive and photovoltaic response [2]. Phthalocyanines are a class of planar aromatic organic compounds that have attracted a great deal of attention for quite some time because of their unique properties such assemiconductivity, photoconductivity, photochemical reactivity, chemical stability, electrochromism, bio-organic and catalytic activity and their application in the field of colour display technology and gas sensors. The electrical, optical and structural properties of phthalocyanine thin films depend on different parameters such as evaporation rate, substrate temperature and post-deposition annealing [3] [4]. In addition to their excellent photoconductive properties, Pc-s have the advantages of being very stable against thermal and chemical decomposition and present very intenseoptical absorption in the visible region. These properties similarity to chlorophyll have many applications in solar cell. Also, they have the potential to serve as active material for molecular electronic devices such as electrochromic displays, chemical sensors and optical data storage. Furthermore, interests in Pc compounds have recently been renewed due to the discovery that they form molecular metals after partial oxidation [5]. The physical properties of thin films materials depend very much on the structure properties; therefore, they have always high priority. The knowledge of the composition of the film is important to understand and predict the nature of the films [6]. Thin films of Phthalocyanines are chemically and thermally durable and are prepared by vacuum thermal evaporation [7] [8] [9]. NiPc is thermally stable and its thin film can be deposited by thermal evaporation without dissociation [10] [11]. A number of analytic techniques are available for the composition characterization of thin films. These include X-ray diffraction studies, AFM and electrical studies. The objective of this paper is to study the effect of thickness on the structural, compositional and electrical studies of Nickel phthalocyanine $(\mathrm{NiPc})$ thin films prepared by vacuum evaporation technique.

\section{Experimental}

Nickel phthalocyanine thin films, with thickness (50, 110, 265 and 350) nm, were deposited on cleaned glass substrate (type corning, China) with dimensions (7.5 $\times 2.5 \times 0.1) \mathrm{cm}$ by thermal evaporation technique (Edwaed coating unit model $306 \mathrm{~A})$ under high vacuum with pressure of $\left(6 \times 10^{-5}\right)$ mbar with deposition rate of about $20 \mathrm{~nm} / \mathrm{min}$. A molybdenum boat was used as a source for the evaporation of the material. Set a distance of $15 \mathrm{~cm}$ to separate the substrate and the boats. The films were characterized by X-ray diffraction technique using (Philips $\mathrm{X}$-ray diffractometer) with $\mathrm{CuK} \alpha$ radiation at wavelength (1.5406) $\mathrm{A}^{\circ}$. Atomic force microscopy was used to determine the roughness snd surface morphology of films. Digital electrometer type Keithly 616 and electrical oven have been used for electrical measurements. The Hall coefficient $\left(\mathrm{R}_{\mathrm{H}}\right)$, carrier type and Hall mobility $\left(\mu_{\mathrm{H}}\right)$ of films were measured by the circuit contain D.C power supply $(0-$ 
40) $\mathrm{V}$ and two digital electrometers (Keithley type 616 to measure the current and voltage

\section{Results and Discussion}

\subsection{X-Ray Diffraction XRD}

X-ray diffraction pattern of NiPc thin film with different thickness (50, 110, 265 and 350) $\mathrm{nm}$ are shown in Figure 1 respectively. XRD pattern indicates that all the samples are single crystal and that it has $\beta$-crystalline phase [12]. The difference between $\alpha$-and $\beta$-phases is attributed to the tilt angle of b-axis of the unit cell. The structure of the NiPc thin film is determined as tetragonal with preferential orientation along the (100) direction. Well-defined diffraction peaks by (100) give the direction of the preferential orientation as deposited film (JCPDS, file No. 11-0744). The diffraction peaks are agreement with the previous observations [1]-[10]. The spacing between the planes (d) has been calculated using the Bragg's formula:

$$
2 d \sin \theta=n \lambda
$$

as shown in Table 1 . The $\mathrm{d}$ values obtained from diffractogram are in agreement with JCPDS record. The differences in the $\mathrm{d}$ values are attributed to higher X-ray absorption, sample purity, particle size, preferred orientation and crystal texture [13] [14]. Table 1 shows the structure parameters of NiPc films, The full width at half maximum (FWHM) intensity of preferential orientation, shows that the FWHM are reduced with increasing thickness except at thickness $350 \mathrm{~nm}$ its increased, which means re arrangement the lattice structure and fill all dangling bind and eliminate the defect [12] [15] [16] and then its increased due to create a localized state at $350 \mathrm{~nm}$. From the Table 1 it is observed that the grain size increases which intern decreases strain and dislocation density. The grain size $D$ of the film is calculated using the Scherrer relation

$$
D=k \lambda / \beta \cos \theta
$$

where $k=0.94$ is a constant, $\lambda$-the wavelength of $\mathrm{x}$-ray, $\beta$-the full width half maximum and $\theta$-the diffraction angle, the grain size increases from (20.85 $33.5 \mathrm{~nm}$ ) for thickness (50-265 nm) and then decreased to 23.2 at $350 \mathrm{~nm}$ as in Figure 2, and this may be attributed to enhancement and re-crystallization these films by increasing the thickness. And the decreasing in grain size at 350 may be attributed to create a localized state by increasing thickness. The intensities of other planes have disappeared. The XRD spectra also shows a little shifting towards lower diffraction angle for (100) plane normally which means greater spacement between atoms which according to Brag equation. The sample which has thickness $265 \mathrm{~nm}$ is the lowest FWHM which means the greatest grain size according to Scherrer equation.

The dislocation density $\delta$ defined as the length of dislocation lines per unit volume of the crystal and can be evaluated from the particle size D by the relation [17]. 

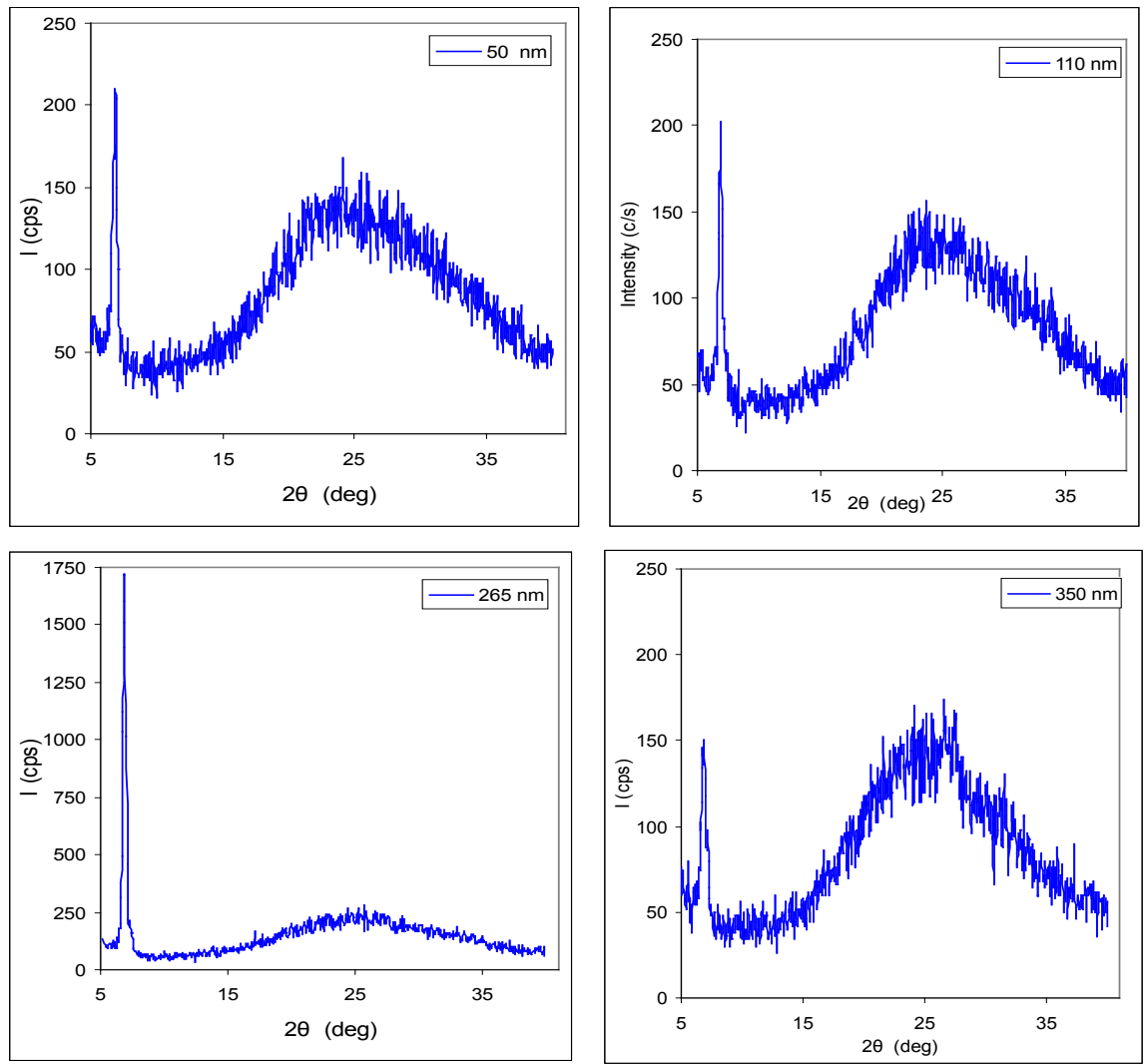

Figure 1. X-ray diffraction of the NiPc thin films with deferent thicknesses.

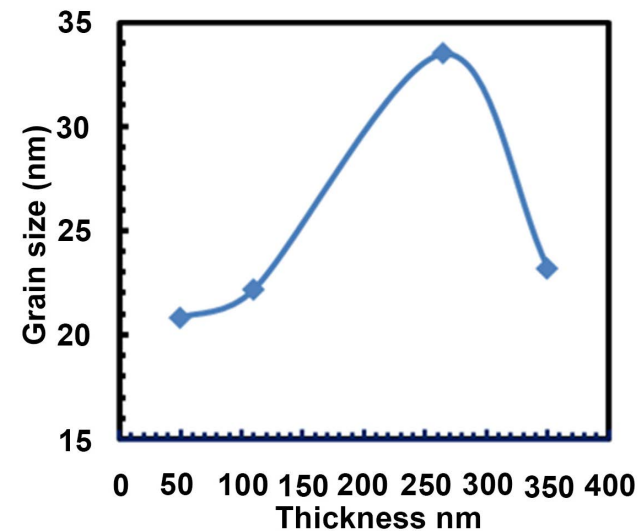

Figure 2. Grain size with thickness of NiPc thin films.

Table 1. X-ray diffraction parameters of the NiPc thin films with deferent thicknesses.

\begin{tabular}{ccccccc}
\hline Thickness nm & $\begin{array}{c}2 \theta \\
(\text { degree })\end{array}$ & $\begin{array}{c}\mathrm{d} \\
\left(\mathrm{A}^{\circ}\right)\end{array}$ & FWHM & $\begin{array}{c}\text { Grain size } \\
(\mathrm{nm})\end{array}$ & $\varepsilon^{*} 10^{-3}$ & $\begin{array}{c}\delta^{*} 10^{-5} \\
\text { Line } / \mathrm{nm}^{2}\end{array}$ \\
\hline 50 & 6.9654 & 12.6804 & 0.3986 & 20.85 & 1.735 & 2.298 \\
110 & 7.0218 & 12.5787 & 0.3735 & 22.2 & 1.625 & 2.018 \\
265 & 7.0068 & 12.6056 & 0.2479 & 33.5 & 1.079 & 0.889 \\
350 & 6.9751 & 12.66282 & 0.3583 & 23.2 & 1.559 & 1.857 \\
\hline
\end{tabular}




$$
\delta=n / D^{2}
$$

where $n$ is a factor, when equal unity giving minimum dislocation density. The microstrain is related to the lattice misfit, which in order depends on the deposition conditions. The microstrain $\mathcal{E}$ is calculated using the relation [17]:

$$
\varepsilon=\beta \cos \theta / 4
$$

Figure 2 and Figure 3 represent the grain size and dislocation density $\delta$ and the microstrain $\varepsilon$ of prepared thin films evaporated with different thicknesses on glass substrates. It was observed that the dislocation density and microstrain exhibit a decreasing trend with the deposition thin film thickness (except at 350 $\mathrm{nm}$ ) which represents better lattice quality.

\subsection{Surface Morphology}

\section{Atomic Force Microscope}

This section of studies includes the effect of thickness on the morphology of prepared films were determined by Atomic Force Microscope with different thickness $\left(50,110,265\right.$ and 350) $\mathrm{nm}$ taken in an area of $10 \times 10 \mu \mathrm{m}^{2}$ as shown in Figure 4. It is observed from the figure that the morphology of these films was uniform surface with clear grain boundaries and growth of crystal and the grain size increases from 48.33 - $203.28 \mathrm{~nm}$ with increasing thickness from 50 - 265 $\mathrm{nm}$ except at thickness $350 \mathrm{~nm}$ its decreased to $91.25 \mathrm{~nm}$ as in Figure 4 and Table 2, and it's decreased at $350 \mathrm{~nm}$ and this is agreement with the results of XRD. Also the typical topography of a polycrystal is observed, where each grain can be clearly individualized. Differences in the height of the grains can also be observed, as well as a visible dispersion of the grain size. It is observed that at 350 of thickness, the grains are somewhat smoothed out. The roughness (rms) of films at different thickness is given in Table 2. It is observed that the roughness increase with thickness increase, and this is agreement with other researchers [18] [19] [20].

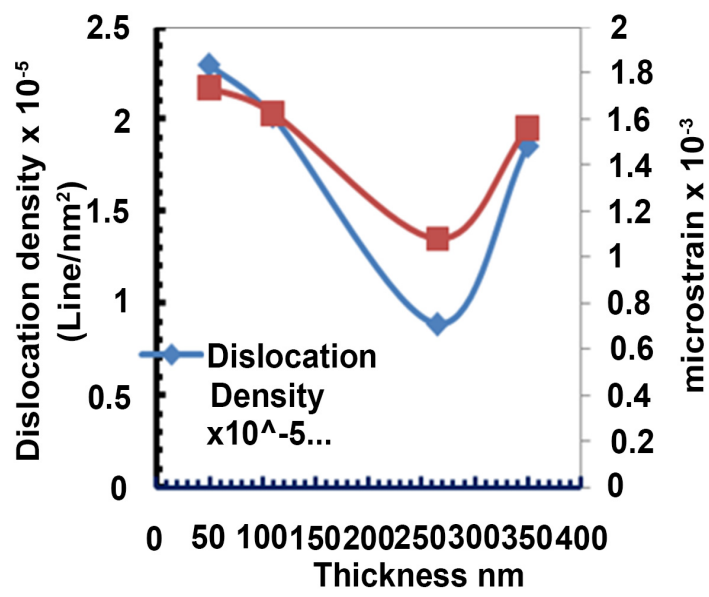

Figure 3. $\delta$ and $\varepsilon$ with thickness of NiPc thin films. 

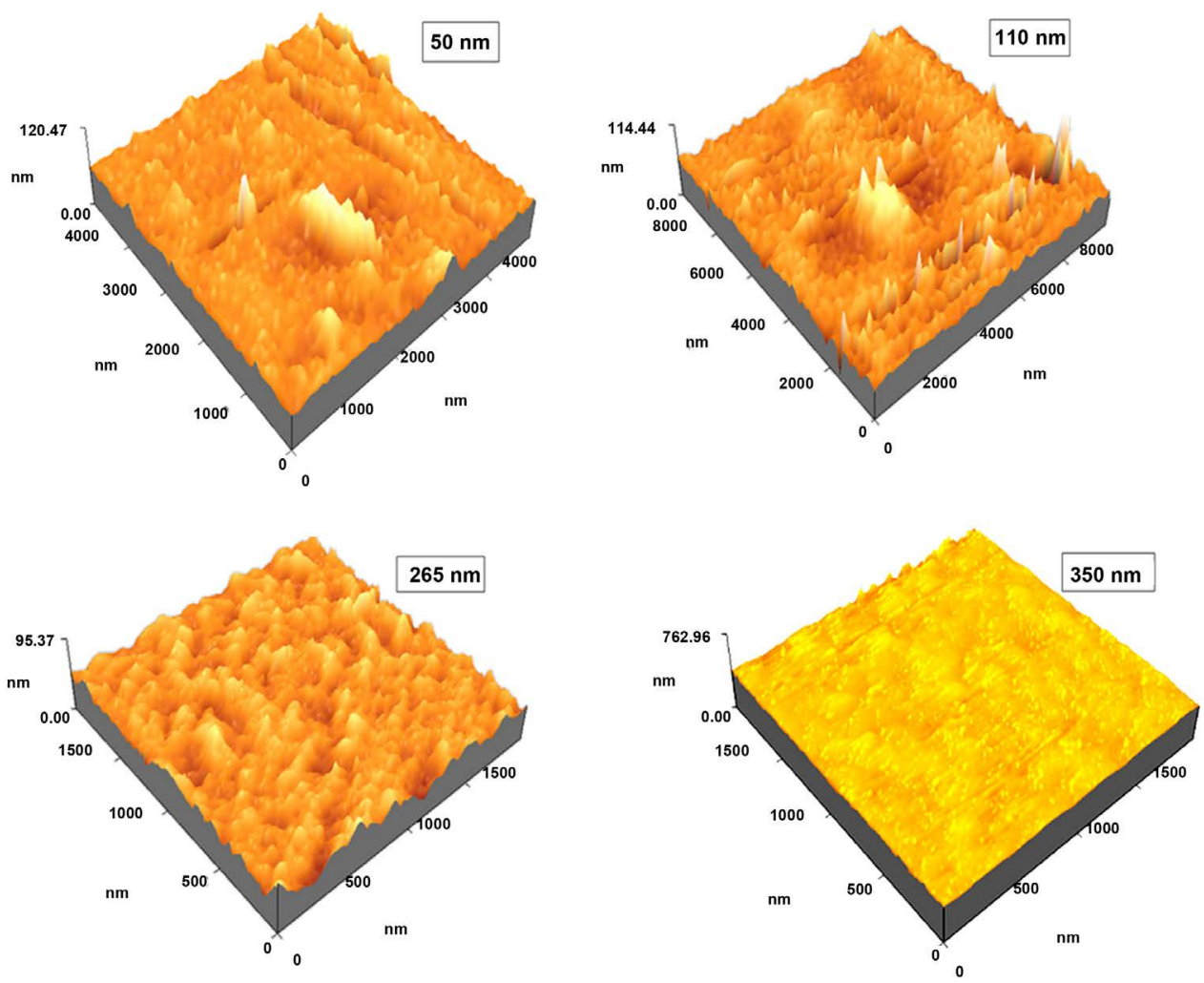

Figure 4. 3-D AFM images of NiPc thin films with different thicknesses.

Table 2. Grain size and average roughness of NiPc thin films by AFM technique.

\begin{tabular}{ccc}
\hline Thickness $(\mathrm{nm})$ & Roughness Average $(\mathrm{nm})$ & Grain Size $(\mathrm{nm})$ \\
\hline 50 & 5.29 & 48.33 \\
110 & 6.2 & 87.17 \\
265 & 6.31 & 203.28 \\
350 & 8.97 & 91.25
\end{tabular}

\section{Electrical properties}

The electrical conductivity of NiPc thin films was performed to determine the thermal activation energy. Measurements were carried out in the temperature range 303 to $473 \mathrm{~K}$ for films with different thickness ranging from 50 to $350 \mathrm{~nm}$. The temperature dependence of the conductivity can be expressed by Arrhenius equation. [11]:

$$
\sigma=\sigma \exp \left(\Delta E / k_{B} T\right)
$$

where $\Delta E$ is the thermal activation energy and $k_{B}$ is the Boltazmann's constant. A plot of $\ln \sigma$ against (1000/T) yields a straight line whose slope can be used to determine the thermal activation energy of the film. Figure 5 shows the dependence of the dark electrical conductivity of as-deposited NiPc films of different thickness on the temperature. Film thickness is one of the most important parameters which affects the physical properties of the films. As seen from the 


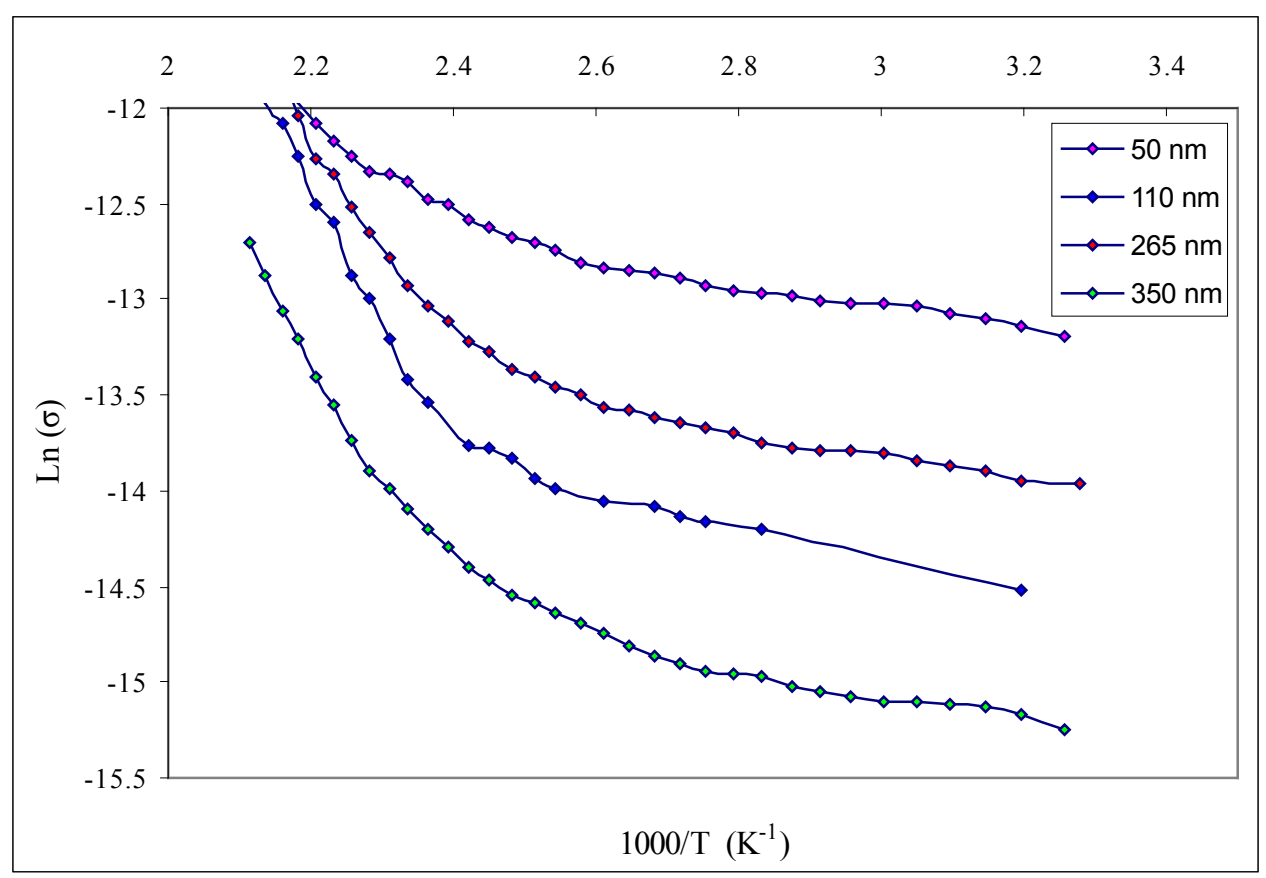

Figure 5. Ln $\sigma$ as a function of $(1000 / \mathrm{T})$ of NiPc thin films for different thicknesses.

figure, there are three semiconductor distinct linear parts, which correspond to three activation energies $\Delta E_{1}, \Delta E_{2}$ and $\Delta E_{3} . \Delta E_{1}$ corresponds to extrinsic region and represents transition process for carriers within localized states in the energy gap and this suggests the existence of high density of localized states in the energy gap, and $\Delta E_{2}$ and $\Delta E_{3}$ corresponds to intrinsic region and represents the carriers transport across the grain boundaries by thermal excitation. The change in the slope and hence the activation energy is interpreted as a change from extrinsic to intrinsic conduction [21]. The value of the thermal activation energy $\Delta E_{1}, \Delta E_{2}$ and $\Delta E_{3}$ is shown in Table 3, which is in good agreement with those obtained by other workers [22] [23]. The room temperature conductivity increases as the thickness increases and this is attributed to the change in the degree of crystallinity. Also, as given in Figure 6, the activation energy varies as the thickness increases and this is because of the improved crystallinity with the increase of the grain size.

\subsection{Hall Effect}

Carrier concentration and Hall mobility have been determined from Hall measurements for NiPc thin films, having different thicknesses which were deposited on glass substrates at $300 \mathrm{~K}$. The Carrier concentration (n) is determined for all film thicknesses and it is of p-type. Hall coefficient $\left(R_{H}\right)$ was calculated, then carrier concentration has been calculated for each thickness and it was of p-type. Carrier mobility was determined for each thickness. All these parameters are shown in Table 4. It can be inferred from the Table that carrier mobility increases with the decrease of the carrier concentration and varies with the increase of film thickness. This is consistent with the work of researchers [23]. 
Table 3. Values of activation energies and conductivity for NiPc thin films with different thicknesses.

\begin{tabular}{cccccccc}
\hline $\begin{array}{c}\text { Thickness } \\
\mathrm{nm}\end{array}$ & $\begin{array}{c}\sigma_{\mathrm{R} . \mathrm{T}} \times 10^{-7} \\
(\Omega \cdot \mathrm{cm})^{-1}\end{array}$ & $\Delta E_{1}(\mathrm{eV})$ & $\begin{array}{c}\text { Temp-Range } \\
(\mathrm{K})\end{array}$ & $\Delta E_{2}(\mathrm{eV})$ & $\begin{array}{c}\text { Temp } \cdot \text { Range } \\
(\mathrm{K})\end{array}$ & $\begin{array}{c}\Delta \mathrm{E}_{3} \\
(\mathrm{eV})\end{array}$ & $\begin{array}{c}\text { Temp } \text { Range } \\
(\mathrm{K})\end{array}$ \\
\hline 50 & 18.524 & 0.051 & $307-333$ & 0.0691 & $338-389$ & 0.156 & $400-454$ \\
110 & 6.476 & 0.076 & $333-369$ & 0.147 & $373-413$ & 0.477 & $413-446$ \\
265 & 8.654 & 0.017 & $305-348$ & 0.099 & $348-403$ & 0.518 & $403-458$ \\
350 & 4.948 & 0.051 & $307-353$ & 0.241 & $363-403$ & 0.603 & $418-473$ \\
\hline
\end{tabular}

Table 4. Values of carrier concentration and carrier mobility for NiPc thin films with different thicknesses.

\begin{tabular}{ccc}
\hline Thickness $(\mathrm{nm})$ & Carrier Concentration ${ }^{*} 10^{12}\left(\mathrm{~cm}^{-3}\right)$ & Carrier Mobility $\mathrm{cm}^{2} / \mathrm{v} . s$. \\
\hline 50 & 11.2 & 13.21 \\
110 & 2.00 & 54.02 \\
265 & 8.68 & 13.32 \\
350 & 1.64 & 15.28 \\
\hline
\end{tabular}

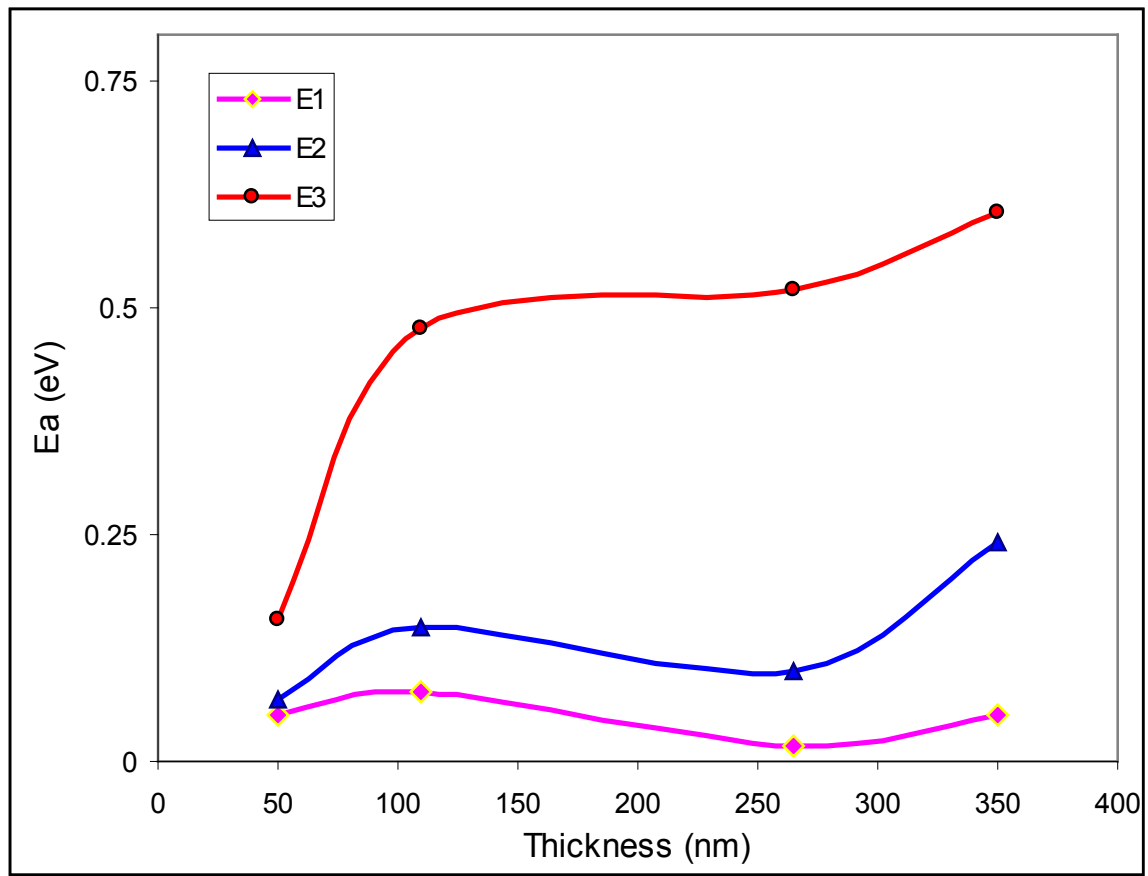

Figure 6. Effect of NiPc thin films thickness on activation energy.

\section{Conclusions}

Thin films of Ni-Pc were prepared by the thermal evaporation method on glass substrates with different thickness successfully. From the x-ray diffraction studies, it is observed that the structure is single crystalline $\beta$-phase film-oriented preferentially (100) plane for all thickness. The structure properties are found to be very sensitive to the thickness of thin film. The grain size increases with in- 
creasing thickness. The change in grain size shows that the properties of $\mathrm{NiPc}$ are controlled by its structure and morphology depending on increases the thickness. The surface morphology of prepared films and the crystal morphology vary with thickness. From the electrical properties measurements, there are three semiconductor distinct linear parts, which correspond to three activation energies $\Delta E_{1}, \Delta E_{2}$ and $\Delta E_{3} . \Delta E_{1}$ corresponds to extrinsic region and $\Delta E_{2}$ and $\Delta E_{3}$ correspond to intrinsic region. Hall effect measurements show that all the films are p-type. The carrier mobility increases with the decrease of the carrier concentration and varies with the increase of film thickness.

\section{Conflicts of Interest}

The authors declare no conflicts of interest regarding the publication of this paper.

\section{References}

[1] Petraki, F., Papaefthimiou, V. and Kennou, S. (2005) A Study of the Ni-Phthalocyanine/Gold Interface Using X-Ray and Ultraviolet Photoelectron Spectroscopies. Journal of Physics: Conference Series, 10, 135-138. https://doi.org/10.1088/1742-6596/10/1/033

[2] Newton, M.I., Starke, T.K.H., Willis, M.R. and McHale, G. (2000) NO Detection at Room Temperature with Copper Phthalocyanine Thin Film Devices. Sensors and Actuators B, 67, 307-311. https://doi.org/10.1016/S0925-4005(00)00542-6

[3] Narayanan Unni, K.N. and Menon, C.S. (2000) Electrical, Optical and Structural Studies on Nickel Phthalocyanine Thin Films. Materials Letters, 45, 326-330. https://doi.org/10.1016/S0167-577X(00)00127-0

[4] Kumar, G.A. (2002) Optical Studies of Phthalocyanine Molecules in PMMA Matrix. Materials Letters, 55, 364-369. https://doi.org/10.1016/S0167-577X(02)00394-4

[5] Kumar, G.A., Jose, G., Thomas, V., Unnikrishnan, N.V. and Nampoori, V.P.N. (2003) NIR to UV Absorption Spectra and the Optical Constants of Phthalocyanines in Glassy Medium. Spectrochimica Acta Part A: Molecular and Biomolecular Spectroscopy, 59, 1-11. https://doi.org/10.1016/S1386-1425(02)00037-9

[6] Kalugasalam, P. and Ganesan, S. (2010) Compositional Analysis of Annealed Lead Phthalocyanine Thin Films. International Journal of Engineering Science and Technology, 2, 2574-2579.

[7] El-Nahass, M.M., Atta, A.A., El-Sayed, H.E.A. and El-Zaidia, E.F.M. (2010) Electrical Transport Mechanisms and Photovoltaic Characterisation of MgPc/p-Silicon Hybrid Organic-Inorganic Solar Cells. Current Organic Chemistry, 14, 84-88. https://doi.org/10.2174/138527210790226447

[8] Hussein, M.T., Eman, M.N. and Senaed, F.A. (2014) Optical Properties of Cobalt Phthalocyanine Thin Films. Indian Journal of Research, 3, 145-147.

[9] Hussein, M.T., Nasir, E.M. and Al-Aarajiy, A.H. (2012) Study on the UV-Visible of Ni-Phthalocyanine Thin Film Optical Properties. International Journal of Thin Films Science and Technology, 1, 71-76.

[10] Fiodorov, M.I. (1999) Gas Sensor. Russia Patent 2124719.

[11] Hussein, M.T., Nasir, E.M. and Al-Aarajiy, A.H. (2013) Structural and Surface Morphology Analysis of Nickel Phthalocyanine Thin Films. Advances in Materials 
Physics and Chemistry, 3, 113-119. https://doi.org/10.4236/ampc.2013.31A014

[12] Joseph, B. and Menon, C.S. (2007) Studies on the Optical Properties and Surface Morphology of Nickel Phthalocyanine Thin Films. E-Journal of Chemistry, 4, 255-264. https://doi.org/10.1155/2007/643834

[13] Kalugasalama, P. and Ganesanb, S. (2010) Surface Morphology of Annealed Lead Phthalocyanine Thin Films. International Journal of Engineering Science and Technology, 2, 1773-1779.

[14] Shihub, S. and Gould, R. (1993) Structure and Phase-Change Phenomena in Evaporated Thin Films of Cobalt Phthalocyanine. Physica Status Solidi (A), 139, 129-138. https://doi.org/10.1002/pssa.2211390110

[15] Ji, Z.G., Wong, K.W., Tse, P.K., Kwok, R.W.M. and Lau, W.M. (2002) Copper Phthalocyanine Film Grown by Vacuum Deposition under Magnetic Field. Thin Solid Films, 402, 79-82. https://doi.org/10.1016/S0040-6090(01)01702-3

[16] Kalugasalam, P. and Ganesan, S. (2010) Structural Analysis of Annealed Lead Phthalocyanine Thin Films. International Journal of Engineering Science and Technology, 2, 2567-2573.

[17] Gopal, S., Viswanathan, C., Karunagaran, B., Narayandass, S.K., Mangalaraj, D. and Yi, J. (2005) Preparation and Characterization of Electrodeposited Indium Selenide Thin Films. Crystal Research and Technology, 40, 557-562. https://doi.org/10.1002/crat.200410383

[18] Aziza, F., Sulaimana, K., Muhammad, M.R., Sayyad, M.H. and Karimov, K. (2011) Influence of Thermal Annealing on the Structural Properties of Vanadyl Phthalocyanine Thin Films: A Comparative Study. International Journal of Materials and Metallurgical Engineering, 5, 693-695.

[19] Larramendi, E.M., Calzadilla, O., Gonzalez-Arias, A., Hernandez, E. and Ruiz-Garcia, J. (2001) Effect of Surface Structure on Photosensitivity in Chemically Deposited PbS Thin Films. Thin Solid Films, 389, 301-306. https://doi.org/10.1016/S0040-6090(01)00815-X

[20] Neghabi, M., Zadsar, M. and Ghorashi, S.M.B. (2014) Investigation of Structural and Optoelectronic Properties of Annealed Nickel Phthalocyanine Thin Films. Materials Science in Semiconductor Processing, 17, 13-20. https://doi.org/10.1016/j.mssp.2013.08.002

[21] Locklin, J. and Bao, Z. (2006) Effect of Morphology on Organic Thin Film Transistor Sensors. Analytical and Bioanalytical Chemistry, 384, 336-342. https://doi.org/10.1007/s00216-005-0137-z

[22] Soliman, H.S., El-Barry, A.M.A., Khosifan, N.M. and El Nahass, M.M. (2007) Structural and Electrical Properties of Thermally Evaporated Cobalt Phthalocyanine (CoPc) Thin Films. The European Physical Journal Applied Physics, 37, 1-9. https://doi.org/10.1051/epjap:2006135

[23] Hussein, M.T., Eman, M.N., Thekra, K. and Senaed, F.A. (2014) Study the Effect of Annealing Temperature on the Structural, Morphology and Electrical Properties CoPc Thin Films. International Journal of Current Engineering and Technology, 4, 3263-3269. 